\title{
A Robust Arctic Amplification Factor Throughout the Last 21,000 Years
}

\section{Yuzhen Yan}

Peking University

Xinyu Wen ( $\nabla$ xwen@pku.edu.cn )

Peking University https://orcid.org/0000-0003-2613-8449

\section{Article}

Keywords:

Posted Date: January 12th, 2022

DOI: https://doi.org/10.21203/rs.3.rs-1111875/v1

License: (c) (i) This work is licensed under a Creative Commons Attribution 4.0 International License. Read Full License 


\section{A Robust Arctic Amplification Factor Throughout the Last 21,000 Years}

3

\section{Abstract}

Arctic amplification ( $\mathrm{AA})$, a phenomenon that a larger change in temperature near the Arctic areas than the Northern Hemisphere average in the past $100+$ years, has significant impacts on midlatitude weather and climate, and therefore is of great concern in current climate projections. Previous studies suggest a wide range of AA factors from 1.0 to 12.5 using either the 20th century observations or climate model hindcasts. In the present paper, we explore the diversity of AA factor in a long-term transient simulation covering the past glacial-to-interglacial years. It is shown that the natural AA phenomenon is essentially linked with North Atlantic sea ice changes through icealbedo feedback with a narrowed and robust AA factor of $2.5 \pm 0.8$ throughout the last 21,000 years. Current observed AA phenomenon is a mixed result combining sea ice melting induced AA mode with GHGs induced global uniform warming, and thus has an AA factor slightly less than 2.5. In the future, as Arctic sea ice gradually melts off, we speculate that AA phenomenon might fade off accordingly and the AA factor will decline close to 1.0 in 1-2 centuries. Our findings provide new evidence for better understanding the range of AA factor and associated key physical processes, and provide new insights for AA's projection in current anthropogenic warming climate.

\section{Introduction}

Arctic amplification (AA) is a prominent mode of modern climate change showing that the nearsurface temperature at high latitudes has a much larger warming rate than the Northern Hemisphere $(\mathrm{NH})$ average during the last $100+$ years in both observations and model simulations ${ }^{[1][2][3]}$. Although AA's impact on mid-latitude weather and climate extremes has been recognized widely ${ }^{[4][5][6][7]}$, its dynamics are complex and still remain controversial ${ }^{[1][8][9]}$. Traditionally, Arctic icealbedo feedback is considered as the basic cause in forming AA ${ }^{[10][11][12]}$. Recently, some researchers argued that the remote processes, such as atmospheric and oceanic meridional heat transport, play an important role in shaping a detectable or considerable AA on Earth-like planets $[13][14][15][16][17][18][19]$ or even on an ice-free planet ${ }^{[20]}$. Besides, it is also found that some local processes, including water vapor and low-cloud increment, can also perform additional warming over Arctic area ${ }^{[2][22]}$. In addition, the lapse-rate constrain, affecting the atmospheric heating 
profiles through both the local and remote (tropical) processes, is also considered as an important mechanism in intensifying near-surface AA ${ }^{[23][24][25]}$. At the current stage, the community still have no consensus on the relative importance among the above candidates, which results in the diverse modeling projections of AA for the next centuries ${ }^{[1][26][27]}$.

AA factor (i.e. AA index), generally defined as the Arctic-to-NH surface warming/cooling ratio to quantify AA's amplitude, is estimated to be in a wide range of 1.3-12.5 in the past 100+ years. Davy et al. ${ }^{[28]}$ did a comprehensive work by investigating 2 sets of observed data and 6 sets of reanalysis data, and suggested that the AA factor could be in 2.5-8.0. With the similar approaches, Bekryaev et al. ${ }^{[29]}$ and Chylek et al. ${ }^{[30]}$ found the AA factor could be in 1.3-2.0 and 2.0-12.5 respectively using weather station records. It should be noted that the calculation of AA factor is sensible to the selection of temporal windows. A shorter temporal window, such as a 30-year or even shorter window, usually brings about the greater variability of AA factor.

The AA factor in modern modeling studies is estimated to be in 1.0-4.5, a wide range still but relatively smaller than those estimates based on the observations. Dai et al. ${ }^{[10]}$ suggested the AA factor can be in the range of 1.2-3.3 by checking 38 model results from the Coupled Model Intercomparison Project Phase 5 (CMIP5) under Representative Concentration Pathway 8.5 (RCP8.5) scenarios. He also emphasized the importance of sea-ice loss in forming AA and pointed out that the AA phenomenon might be vanished once Arctic sea ice melt off. In a similar study, Barnes et al. ${ }^{[31]}$ argued the AA factor could be in the range of 1.0-2.0 by visiting 5 CMIP5 models. In addition to these projections, some sensitive experiments including $\mathrm{CO} 2$ doubling or quadrupling runs also give diverse estimates of AA factor. Stuecker et al. ${ }^{[25]}$ examined the modeled $4 \mathrm{xCO} 2$ snapshots in CESM and concluded that the AA factor can be around 2.0. Three earlier studies using similar $2 \mathrm{xCO} 2$ or $4 \mathrm{xCO} 2$ configurations showed the range of AA factor could be in 1.9-2.0 ${ }^{[32]}, 1.2-2.4^{[33]}$, and $1.5-4.5^{[34]}$, respectively.

The AA factor in paleoclimate modeling studies is estimated to be in 1.0-6.0. Park et al. [35] investigated the differences between mid-Holocene (6ka, $\mathrm{MH})$ and pre-industrial $(\mathrm{PI})$ snapshots in 13 models from the Paleoclimate Modelling Inter-comparison Project, Phase 3 (PMIP3) and concluded that the AA factor can vary in the range of 1.3-6.0, which is apparently larger than the estimation made by other proxy studies, i.e. 1.5-2.2 ${ }^{[36][37][38]}$. An earlier modeling study done by 
Masson-Delmotte et al. ${ }^{[39]}$ show the range of AA factor for LGM-to-PI changes in 6 PMIP2 models can be 1.0-2.9, slightly lower than 3.6, a median estimated by reviewing a few proxy studies in Miller et al. ${ }^{[40]}$. Please note that significant uncertainties may exist in both the paleoclimate modeling and the proxy studies. For the paleoclimate modeling studies, those AA factors estimated with MH-to-PI or LGM-to-PI snapshots actually reflect an extremely slow adjusting process in the climate system on the timescale of 1,000-to-10,000 years, rather than a fast climatic response on the centennial timescale as discussed in the observation-based studies. For the proxy studies, the uncertainty is mainly raised by the spatially sparse records, which hardly represent either Arctic or the $\mathrm{NH}$ average climate.

Re-visiting AA from paleoclimate modeling point of view can provide us more clues on its long-term variability and dynamics. Differing from common snapshot modeling approach, such as the PMIP, here we analyze the evolution of AA in the project of Simulation of Transient Climate Evolution over the last 21,000 years (TraCE-21ka), a paleoclimate modeling project done by Liu and Otto-Bliesner ${ }^{41]}$. More details regarding the model and experiments designed in TraCE-21ka can be found in the Method section. This long-term transient simulation benefits our research in 2 ways: 1) to make it possible to calculate AA factors throughout the last 21,000 years on an exact 100-year temporal window, a comparable timescale as discussed in previous observation-based studies; and 2) to make it possible to present a wide spectrum of AA factors with a mass of 100-year samples that have complete spatial (NH) and temporal (annual mean data for 100 years) coverage. These advantages can effectively reduce the uncertainties raised in previous snapshot modeling and proxy studies. We hope to demonstrate the diversity of AA factors in the last 21,000 years and discuss its dominant mechanism.

\section{AA in modern and paleo-climate}

The spatial pattern of AA in modern warming climate is generally featured with a major warming center around Arctic and a minor warming at NH low- to mid- latitudes (Fig. 1a,b). The scientists tend to define AA factor as the ratio of surface air temperature (SAT) changes at high-latitudes to NH average within a specific time window ${ }^{[28]}$. The observations in the past $100+$ years, however, are insufficient to deliver a clear AA spatial pattern, since the SAT trends derived from 4 commonly 
used datasets show diverse AA patterns with large uncertainty (Supplementary Fig. 1), mainly due to their sparse records over Arctic and oceans in the early 20th century. Instead, the multi-model means of historical and future simulations from the Coupled Model Inter-comparison Project, Phase 6 (CMIP6) can present a distinct zonal AA pattern for the past 100+ years (Fig. 1a) and the near future (Fig. 1b). The current AA pattern, as a result of anthropogenic forcing plus natural variabilities, comprises simultaneously the uniformly global warming and polar amplification signal. We can see this pattern clearly in the CMIP6 estimates for the 20th century (Fig. 1a) and the 21th century (Fig. 1b). But in the much longer future, say 2151-2250 in CMIP6 extension scenarios (Fig. 1c), AA tends to disappear largely even when the CO2 concentration keeps increasing from $1751 \mathrm{ppm}$ to 2206 ppm, reminding us that AA might not be linked with $\mathrm{CO} 2$ forcing as tightly as in the observations. Hence, it is much helpful to separate the AA pattern related to sea ice melting as an independent internal mode of climate system from current human-induced global warming framework.

The paleoclimate simulation TraCE-21 ka can reproduce as similar spatial pattern of AA as the CMIP6 estimates for a series of abrupt climate change (ACC) intervals in the last 21,000 years. Here, we show the SAT trend during a 100-year window in Bølling-Allerød (BA) warming period as an example (Fig. 1d). It shows that paleo-AA pattern is also featured with a major warming center around Arctic but very small warming at low- to mid- latitudes (Fig. 1d). In addition, the AA patterns in CMIP6 and TraCE-21ka share another common feature that the significant SAT warming normally occurs at the areas where sea ice melts rapidly (white dotted areas in Fig. 1a,b,d), suggesting that sea ice changes play an important role in shaping AA pattern, which will be discussed in-depth in the following sections.

What is the range of AA factor across the last 21,000 years? Here we examine this value in three datasets, including TraCE-21ka covering the last 20,000+ years, NOAA-NCEI/LMR covering the last 2000+ years, and NOAA-CIRES/20CR covering the last 100+ years. The results are shown in Fig. 2 with 1972 samples from TraCE-21ka (Fig. 2a, navy blue, green, steel blue dots), 1901 samples from NOAA-NCEI/LMR (Fig. 2a, orange dots), and 1 single sample from NOAACIRES/20CR (Fig. 2a, red cross). Each sample refers to one AA factor (see Method, for the detailed definition) within a 100-year window. We can see those TraCE-21ka dots scattering in a diamond shape that reflect two distinguished climatic states. The first state features 1654 samples in total 
close to the y-axis, referring to those samples having relatively stable 100 -year climate with $\mathrm{NH}$ averaged temperature changing less than $0.2^{\circ} \mathrm{C} / 100 \mathrm{a}$, which acts as a small denominator and makes the AA factors vary largely from -15 to +20 . The second state includes 318 samples in total at 3 o'clock and 9 o'clock directions, representing those intervals, mostly in deglaciation years, having significant warming or cooling trends with NH SAT trend greater than $0.2^{\circ} \mathrm{C} / 100 \mathrm{a}$. In such cases, AA factors almost stabilize around the level of 2.5 (see Method and Supplementary Fig. 2). Similarly, the NOAA-CIRES/20CR sample (Fig. 2a, red cross) also presents an estimate of AA factor at 2.43 for the 20th century, a value slightly less than the estimate from TraCE-21ka. The NOAANCEI/LMR samples (Fig. 2a, orange dots), however, give an estimate of AA factor in a wide range of 0-5, since Earths' climate was quite stable in the last 2,000 years with $\mathrm{NH}$ averaged temperature varying almost no more than $0.4{ }^{\circ} \mathrm{C} / 100 \mathrm{a}$ even in either the Medieval Warm Period (MWP) or the Little Ice Age (LIA), which can be compared to the first climatic state in TraCE-21ka. Overall, the majority of AA factors in both state 1 and state 2 fall in a narrow spread around 2.5 (Fig. 2a).

We further precisely examine the uncertainty of AA factors in TraCE-21ka data by investigating the weighted probability density functions (Fig. 2b,c). It is shown that all the 1972 samples of AA factors follow a gaussian distribution with 2.5 as the median and \pm 0.8 as two wings accounting for $50 \%$ total variance, i.e. the range from 25 th to 75 th percentiles. This narrowed factor, $2.5 \pm 0.8$, implies a robust AA phenomenon is one of the internal modes of Earth's fluctuated climate in the last 21,000 years, suggesting that the natural processes within climate system may play a more important and robust role in shaping AA rather than modern anthropogenic forcing.

\section{Three AA modes in the last 21,000 years}

What do the scattering points imply in difference regimes in Fig. 2a? To address this question, we perform composite analysis on those points over various regimes and name them in 3 modes (Fig. 3): the Arctic Mode with two phases AM+ and AM- (Fig. 3h, purple areas) standing for samples at 3 o'clock and 9 o'clock directions of the diamond shape; the Warm-arctic-Cold-tropics Mode, WCM+ and WCM- as two phases (Fig. 3h, green areas), standing for dots at the right wing of 12 o'clock direction and the left wing of 6 o'clock direction respectively; and the Cold-arctic-Warmtropics Mode, CWM+ and CWM- (Fig. 3h, yellow areas), standing for dots at the y-axis symmetric 
positions to WCM modes. These names describe the major features of SAT trend in the NH (Fig. 3a-f), whereas the sign, as the name's postfix, indicates the NH averaged SAT trend being positive or negative (Fig. 3g). The samples in the center of the diamond are not taken into analysis, since their features are not distinct.

The 136 samples in Arctic Mode (AM+ and AM-), mostly in the last deglaciation, indicate those snapshots of Earth experiencing abrupt climate change with NH averaged SAT significantly warming or cooling more than $0.2{ }^{\circ} \mathrm{C}$ within 100 years (Fig. 3h, purple areas). The composite Arctic Mode implies that the SAT changes mostly occur at extra-tropics and even high-latitudes, especially surrounding the North Atlantic regions (Fig. 3a,b). In contrast, the temperature changes in the tropics are secondary and subtle. That is why we name these cases as the Arctic Mode by emphasizing the essential role of Arctic temperature changes in dominating the NH averaged climate changes, whereas the tropical temperature remains unchanged or slightly changed (Fig. 3g). Here, we develop a simplified model to depict this pattern by defining a critical latitude separating high-latitude major warming/cooling from low-latitude minor warming/cooling, which could be valid ranging from 36.8N to $60 \mathrm{~N}$ (Supplementary Fig. 3a, red line, black lines, and blue line). Those composite Arctic Mode patterns (Fig. 3a,b) approximately correspond to the condition with a critical latitude close to 37N (Supplementary Fig. 3a, red line), suggesting that high sea ice extent in the last deglaciation induce a more extensive AA phenomenon and less tropical changes than in the Holocene with low sea ice extent conditions (Supplementary Fig. 3a, blue line). In short, Arctic Mode is the most important and typical mode among the three AA modes (Fig. 3g,h) by demonstrating a typical and distinct AA configurations when the $\mathrm{NH}$ mean climate significantly inclines. In the past 21,000 years, Arctic Mode mainly occurred in the last deglaciation (Fig. 2, green dots and lines) and some ACC intervals in the Holocene (Fig. 2, steel blue dots and lines) by featuring a southerly expanded Arctic warming/cooling pattern (Fig. 3a, b) with an AA factor at $2.5 \pm 0.8$ (Fig. 2c).

The samples in Warm-arctic-Cold-tropics Mode (WCM+ and WCM-), as well as Cold-arcticWarm-tropics Mode (CWM+ and CWM-), represent the snapshots of Earth experiencing stable climate when NH temperature has small centennial trend (Fig. 3h, green for WCM and yellow for CWM) since high- and low- latitudes have comparable but opposite temperature trends (Fig. 3 c,d for WCM, e,f for CWM). The differences between WCM+ and WCM- (CWM+ and CWM-) are the 
warming (cooling) at high-latitudes is slightly overwhelming, so that the NH average also appears a faintly warming (cooling), and vise versa.

What about the zonal-mean structure of the three modes? We perform composite analysis on temperature trends at multiple pressure levels, and obtain the zonal mean features of the three modes, as shown in Fig. 4. In Arctic Mode (Fig. 4a, b), there is significant warming/cooling in extra-tropics extending from the surface to $500 \mathrm{hPa}$, whereas in tropics there is also considerable warming/cooling in the upper-troposphere from $500 \mathrm{hPa}$ to $150 \mathrm{hPa}$, the so-called "mini global warming" or "tropical amplification" in the literatures ${ }^{[42]}$, but in apparently weaker amplitude than that in the Arctic surface. In the plots for WCM and CWM modes (Fig. 4, c-f), no significant temperature trends (dotted areas in Fig. 4) can be found in the troposphere except for the slight nearsurface warming/cooling at high latitudes, but with very low statistical significance. In general, the WCM and CWM modes have no statistically significant features on either spatial maps (Fig. 3c-f) or cross-section views (Fig. 4c-f), indicating that they can be seen as climatic noises rather than a typical AA mode.

The spatial pattern and vertical structure of the three modes hint us that the Arctic Amplification phenomenon, in nature, might be closely linked to sea-ice-air coupling processes happening over the North Atlantic sector. The AM mode composite represents a typical changing climate (Fig. 3a,b) that some sea-ice related large-scale low-frequency (close to or even longer than centennial timescale) forcing, such as the Atlantic Multi-decadal Oscillation (AMO) or the Atlantic Meridional Overturning Circulation (AMOC), trigger ice-albedo positive feedbacks, which further causes abundant sensible heat released from the upper ocean to the lower atmosphere. Fig. 1d, for instance, gives a 100-year example in Bølling-Allerød period showing that the fast warming (Fig. 1d, red shadings) area over the North Atlantic is essentially caused by the ocean's heat release due to sea ice melting (Fig. 1d, white dots). The cases in the other 2 modes imply that the NH climate is overall stable with minor internal high-frequency climatic oscillation or disturbance, such as the Arctic Oscillation (AO) and/or the Pacific Decadal Oscillation (PDO), but without ice-albedo feedback triggered (Fig. 3c-f, no dots over North Atlantic or North Pacific). In the next section we would discuss the contribution of sea-ice melt (or freeze) to AA's formation. 


\section{Key sea-ice process in shaping AA}

201

202

203

204

205

206

207

208

209

210

211

212

213

In order to identify the physics associated with AA phenomenon, we explore the variations of Arctic sea ice areas and $\mathrm{CO} 2$ concentrations for all the ACC snapshots, which is defined here as a 100 -year sample having SAT trend larger than $\pm 0.5^{\circ} \mathrm{C} / 100$ a (Fig. 5a). Most of these cases, which belong to $\mathrm{AM}+$ and $\mathrm{AM}-$ modes for sure, are in the Bølling-Allerød (BA) interstadial, while the rests are in the recovery phase of Younger Dryas (YD), the 8.2ka event, and other ACC events in the Holocene (Fig. 5a, purple circles). Fig. 5b and 5c show the AA factor with respect to the 100a-window trend of $\mathrm{NH}$ sea-ice and $\mathrm{CO} 2$ respectively. The purple points scatter in the regimes at 3 o'clock and 9 o'clock directions, in Fig. 5b, suggesting a robust bond between sea ice expansion/retreat and AA formation in those ACC epochs. However, the purple points scatter randomly around the zero point in $\mathrm{x}$-axis (Fig. 5c), suggesting that a typical AA event can even happen without significant $\mathrm{CO} 2$ increase/decrease. Alternatively, it is implied that the rapid change of sea ice, rather than $\mathrm{CO} 2$ concentration, might be the direct and solid reason for AA's formation.

The sea ice changes on centennial timescale induce Arctic temperature response, i.e. AA pattern, through a series of thermodynamic processes. By taking a NH warming case as an example, sea ice melting exposes more low-albedo sea surface water absorbing more downward solar radiation ${ }^{[10][12]}$, which further results in more heat release from oceanic mixed layer to the lower troposphere in autumn that delays the ice freeze ${ }^{[43][44]}$. In this situation, newly frozen ice is relatively thin, and is quite easy to melt further in the next summer. This ice-albedo positive feedback process leads to a rapid increase of surface temperature surrounding the sea ice melting areas, i.e. the Arctic Amplification pattern shown in Fig. 1a,b,d. It should be noted that the entire processes are natural within the sea-ice-air system, triggered by a variety of low-frequency sea-ice-air coupling process (in paleoclimate) or anthropogenic GHGs forcing (in modern climate). Hence, it could be more accurate to attribute current AA phenomenon to sea ice melting near North Atlantic and Barents/Kara seas rather than the human-induced GHGs increasing. Jekins and Dai ${ }^{[45]}$ also confirmed the importance of sea ice loss rather than other causes in forming AA in a cutting-edge climate model. Ideally, we can speculate that a very weak or even no AA pattern can be expected before sea-ice starting melting or after its melting off, even if anthropogenic emission of $\mathrm{CO} 2$ continued (Fig. 1c, Fig. 5c). 
Let us go back to Fig. 1 again to discuss the diversity of AA patterns in the past, present, and

the future. In the last and the future 100 years (Fig. 1a,b), anthropogenic CO2 is persistently warming Earth's surface, resulting in subsequent sea ice melting that further amplifies the near surface warming in Arctic. Thus, the current observed warming pattern accounts for not only the CO2-induced global warming (Supplementary Fig. 3b, grey shadings) but also the AA outcome (Supplementary Fig. 3b, blue line). Thus, the AA factor tends to be less than 2.5 but greater than 1 (Supplementary Fig. 3b), e.g. they are 2.36 and 1.76 for Fig. 1a and $1 \mathrm{~b}$ respectively. In the paleoclimate context, there was not such massive and rapid $\mathrm{CO} 2$ increase/decrease due to anthropogenic activities. But sea ice melt/freeze still happened naturally, which also introduced a clear and distinct AA mode, i.e. Arctic Mode, by a AA factor of 2.5 \pm 0.8 approximately (Fig. 1d, Fig. 2c, Fig. 3a,b, Supplementary Fig. 3a). In the long-term future, by taking the years of 2151-2250 from CMIP6 extended projections as an example, the AA factor is reduced down to 1.14 (Fig. 1c), implying that the AA phenomenon will be weakened dramatically or even disappear, since the summertime sea ice already melts off and ice-albedo positive feedback accordingly shuts down. In other words, even anthropogenic GHGs still keep rising, the surface warming pattern simply appears to be globally uniform, partly plus land amplification through vegetation feedbacks (Fig. 1c). We cannot expect to find a clear Arctic amplification phenomenon anymore and the AA factor should be reduced down to 1.x approximately.

\section{Conclusions}

Our work shows the diversity of AA factor in the last 21,000 year in a transient simulation. From the modeling point of view, we conclude that the AA phenomenon in nature is linked with sea-iceair coupling through ice-albedo feedback process, which could be triggered by either natural climatic variability in ancient times or by anthropogenic forcing, like GHGs, in current global warming centuries. In paleoclimate context, AM mode presents a typical and distinct AA structure with a robust AA factor around $2.5 \pm 0.8$ when $\mathrm{NH}$ climate rapidly changed, whereas $\mathrm{WCM}$ and CWM modes present abnormal AA structure with a largely varying AA factor from -15 to 20 when $\mathrm{NH}$ climate is relatively stable. In current climate context, the AA factor is slightly less than 2.5 since the observed warming pattern includes not only sea-ice-induced AA but also GHGs-induced uniform warming. In future climate context, we estimate that the AA factor will gradually decrease 
down to 1.x when Arctic sea ice completely melt off, leaving a GHGs-induced warming NH without AA phenomenon.

This work has some uncertainties regarding the definition of AA factor, especially in terms of the latitudinal range of Arctic region and the temporal window chosen for computing linear trends of SAT. For the first parameter, we tested various definitions of Arctic region as north of $45 \mathrm{~N}, 50 \mathrm{~N}$, $55 \mathrm{~N}, 60 \mathrm{~N}, 65 \mathrm{~N}$, and 70N (Supplementary Fig. 5a-f). The results indicate that the distribution of AA factor is not sensitive to the selection of Arctic region definition. For the second parameter, we tested several windows like 8-year, 16-year, 32-year, 64-year, 128-year, and 100-year (Supplementary Fig. 7a-f). It seems that the distribution of AA factor is quite sensitive to this parameter and changes largely. Considering the stability of AA factor and the convenience of data processing, we choose 100 -year as the temporal window in this article. For more information regarding the definition of AA factor, the statistical method, and some schematic diagrams, please find in the method section.

Some interesting questions still remain open, such as why the natural AA factor falls into the range of 1.7-to-3.3 with the median value at 2.5? What about the Antarctic amplification on the glacial-to-interglacial timescale? Is there any correlation between these two polar amplification signals ${ }^{[46]}$ ? We need to collect more evidence from both the proxies and modeling results to figure them out, which will definitely further improve our understanding of polar amplification dynamics and provide direct insights for the current climate projections.

Note: The information about author list \& contributions, acknowledgements, and competing interests are temporally hided for double-blinded peer review. 


\section{AA factor}

The AA factor in this article is defined as

$$
y_{n}=\left[\frac{\text { trend_Arctic }}{\operatorname{trend} \_N H}\right]_{\text {win }}=\frac{\operatorname{avg}\left(T_{(n, n+w i n / 2)}^{A r c t i c}\right)-\operatorname{avg}\left(T_{(n-w i n / 2, n)}^{A r c t i c}\right)}{\operatorname{avg}\left(T_{(n, n+w i n / 2)}^{N H}\right)-\operatorname{avg}\left(T_{(n-w i n / 2, n)}^{M H}\right)}
$$

Where $y_{n}$ is the AA factor on the $\mathrm{n}^{\text {th }}$ time point, win is the time window, here we choose 100 years (Discussion on its sensitivity, see below) to calculate the linear trends. $T$ is $2 \mathrm{~m}$ air temperature. Arctic region is defined as $60^{\circ} \mathrm{N}-90^{\circ} \mathrm{N}$ (Discussion on its sensitivity, see below). Factors with $\mathrm{NH}$ trends less than $0.02{ }^{\circ} \mathrm{C} / 100 \mathrm{a}$ are discarded, since they are physically unrealistic due to near-zero denominator problem. As a result, there are 1972, 1901, and 1 valid samples extracted from TraCE$21 \mathrm{ka}, \mathrm{NOAA}-\mathrm{NCEI} / \mathrm{LMR}$, and NOAA-CIRES/20CR respectively.

\section{The selection of Arctic region}

291 Arctic region in the calculation of AA factor is defined as $60^{\circ} \mathrm{N}-90^{\circ} \mathrm{N}$, in order to fit in previous 292 Arctic Amplification related literatures. Considering North Atlantic sea ice expanding to lower latitudes in glacial period, and shrinking in deglaciation and interglacial period (Supplementary Fig. 4), we also examine AA factor distribution with other definitions of the Arctic region from $45^{\circ} \mathrm{N}$ $90 \mathrm{~N}$ to $70^{\circ} \mathrm{N}-90 \mathrm{~N}$ (Supplementary Fig. 5). Results show that no significant distinction of AA factor distributions can be found with different Arctic region definitions. In another word, AA factor is not sensitive to the selection of Arctic regions.

\section{The selection of temporal window}

299 We tested temporal windows with different length of years for AA factor's calculation using NOAA300 CIRES/20CR data (Supplementary Fig. 7 and 8). The results show that when the length of temporal 301 window is less than 64 years, temperature changes are influenced largely by high frequency internal climate variabilities. When time window is greater than 100 years, AA factors are stabilized around $2-6$, consistent with previous literatures. In this study, we choose 100-year as the temporal window 
for AA factor's calculation, which is fairly good length for computing Arctic and NH temperature changes in a typical AA case.

\section{The robust AA factor 2.5}

We investigated the robustness of AA factor with two methods. For the first method, we simply calculate the linear regression coefficients of Arctic temperature change over $\mathrm{NH}$ temperature change in TraCE-21ka, and find the best fit of the slope is 2.46 (Supplementary Fig. 2). For the second method, we calculate the distribution of all AA factors in TraCE- $21 \mathrm{ka}$ by multiplying their corresponding $\mathrm{NH}$ temperature change as weights. In this method, those AA factors with larger $\mathrm{NH}$ temperature changes have larger weights, i.e. highlighting the points at 9 o'clock and 3 o' clock directions of the diamond shape (Fig. 2a), since we want to capture the features of typical AA phenomenon under significant climate change. In addition, we test different bins in counting the distributions and finally choose 0.05 as a proper value that can balance systematical and sampling errors (Supplementary Fig. 6). As the final step, we perform a Gaussian fitting on the weighted distribution of AA factors and find the median is 2.5 with \pm 0.8 spreads accounting for its $50 \%$ total variance (Fig. 2c).

We also checked the credibility of our findings by comparing the AA factors in TraCE-21ka with those in PMIP3 snapshots (Supplementary Fig. 2b). The best fitting slope of eight models' results in PMIP3 is 2.33, which is very close to 2.32 in TraCE-21ka, suggesting that the results of transient simulation TraCE-21 ka are reliable. It should be noted that the value 2.33 or 2.32 here is derived from glacial-to-interglacial timescale rather than aforementioned 2.5, which is derived from centennial timescale. A further discussion on the discrepancy of these two figures (Supplementary Fig. 2a and $2 b)$ is beyond the scope of this paper.

\section{A simplified AA model}

We simplify the typical AA into a conceptual model in order to better understand its essential features (Supplementary Fig. 3). For the natural AA mode, it is assumed that the NH average warming rate is $1{ }^{\circ} \mathrm{C} / 100 \mathrm{a}$, and there exists a critical latitude, north of which (so-called Arctic region) is uniformly warming at the rate of $2.5^{\circ} \mathrm{C} / 100 \mathrm{a}$, and south of which is uniformly warming at the 
331 rate of $X{ }^{\circ} \mathrm{C} / 100$ a (Supplementary Fig. 3a). Thus, the AA factor has the unchangeable value 2.5, but 332 the critical latitude can vary with the changing low-latitudes warming rate $\mathrm{X}$. By assuming the above 333 conditions, all valid configurations are illustrated with red (the southernmost critical latitude), black, 334 and blue lines (the northernmost critical latitude). In the paleoclimate context, the composite 335 analysis show that the natural AA pattern is very similar to the red line, where the critical latitude is 336 close to $37 \mathrm{~N}$ (Fig. 3a, b), partly because of the greater sea ice extent than present. However, for the 337 anthropogenic AA mode, a uniform hemispheric warming is added over the natural AA mode 338 (Supplementary Fig. 3b), i.e., global warming plus AA, causing the ratio of Arctic warming to NH 339 averaged warming is less than 2.5. The modern observations almost correspond to the blue line in 340 the Supplementary Fig. 3b. For example, the AA factors in 1901-2000 in NOAA-CIRES/20CR and 341 CMIP6 are 2.43 and 2.36 respectively. 
TraCE-21ka The project of Simulation of Transient Climate Evolution over the last 21,000 years (TraCE-21ka) provides us key information from the Last Glacial Maximum (LGM) to the present climate. The model used in this projection is the Community Climate System Model version 3 (CCSM3), which couples the dynamic vegetation model (DGVM), the Community Atmospheric Model 3 (CAM3), the Parallel Ocean Program (POP), and the Community Sea Ice Model (CSIM). TraCE-21ka successfully reproduces a series of paleoclimate events and key processes, such as Heinrich Stadial 1 (H1), Bølling-Allerød (BA), and Younger Dryas (YD). All the TraCE-21ka outputs and documents can be found at https://www.cgd.ucar.edu/ccr/TraCE/.

PMIP3 We adopt snapshot simulations from eight models in the Paleoclimate Modelling Intercomparison Project 3 (PMIP3), a coordinated model experiment project to give snapshots of 21ka, 6ka and 0ka. The 8 models used in this work include 1) GISS-E2-R, 2) MIROC-ESM, 3) FGOALSg2, 4) MPI-ESM-P, 5) IPSL-CM5A-LR, 6) MRI-CGCM3, 7) CNRM-CM5, and 8) CCSM4. More descriptions and data can be found on the website https://pmip3.1sce.ipsl.fr/.

NOAA-NCEI/LMR The project of Last Millennium Reanalysis (LMR) version 1 led by National Oceanic and Atmospheric Administration (NOAA) and National Centers for Environmental Information (NCEI) provides us the complete reanalysis data covering the last two millenniums. Outputs include 20 Monte Carlo runs for the period 1-2000 C.E. Please see Hakim et al. ${ }^{[47]}$ for more information and find the data at https://www.atmos.uw.edu/ hakim/LMR/.

NOAA-CIRES/20CR The project of 20th Century Reanalysis Version 2c (20CR V2c) led by National Oceanic and Atmospheric Administration (NOAA) \& Cooperative Institute for Research in Environmental Sciences (CIRES) provides us monthly $2 \mathrm{~m}$ air temperature from 1851/1 to 2014/12. More details can be found at https://psl.noaa.gov/data/gridded/data.20thC ReanV2c.html.

GISTEMP v4 The project of Surface Temperature Analysis from NASA Goddard Institute for Space Studies version 4 (GISTEMP v4) provides combined ocean and land surface temperature on a $2^{\circ} \times 2^{\circ} \mathrm{C}$ grid covering the period 1880 -present. This dataset is well-known for its strength of satellite observations. Descriptions see the website http://data.giss.nasa.gov/gistemp/. 
CRU TS4 The project of Climatic Research Unit (CRU) Time-series version 4 (TS4) datasets provides high-resolution $\left(0.5^{\circ} \times 0.5^{\circ}\right)$ land-only near-surface temperature monthly data. The observations are derived primarily from $4000+$ weather stations worldwide covering the period 1901-present. More information see the website http://badc.nerc.ac.uk/data/cru/.

ERA 20C The project of 20th Century Reanalysis from European Center for Medium-Range Weather Forecasts (ECMWF) (ERA 20C) provides us monthly $2 \mathrm{~m}$ temperature. It assimilates observations of surface pressure and surface marine winds and generates the reanalysis with horizontal resolution around $125 \mathrm{~km}$ (spectral truncation T159) covering the period 1900-present. More information please see the website https://ecmwf.int/en/forecasts/datasets/reanalysisdatasets/era-20c.

CMIP6 Eight models from the Coupled Model Inter-comparison Project Phase 6 (CMIP6) are used to reproduce modern historical climate and future projections under the Shared Socioeconomic Pathways 5-8.5 (SSP5-8.5) scenarios ${ }^{[48]}$, including 1) CESM2, 2) CMCC-CM2-SR5, 3) FGOALSf3-L, 4) CanESM5, 5) FIO-ESM-2-0, 6) UKESM1-0-LL, 7) E3SM-1-1, and 8) CIESM2. Given the data availability, only four of them, including 1) MRI-ESM2-0, 2) IPSL-CM6A-LR, 3) UKESM10-LL, and 4) CanESM5, are used to estimate long-term future climate for the period 2151-2250 as the extension of SSP5-8.5. The SSP5-8.5 scenario can be compared to the Representative Concentration Pathway 8.5 (RCP8.5) scenario in the Coupled Model Inter-comparison Project Phase 5 (CMIP5) ${ }^{[48]}$. Descriptions of the CMIP6 project can be found on the website https://www.wcrp-climate.org/wgcm-cmip/wgcm-cmip6. 


\section{References}

1. Serreze, M. C. \& Barry, R. G. Processes and impacts of Arctic amplification: A research synthesis. Glob. Planet. Change 77, 85-96 (2011).

2. Collins, M. et al. Climate Change 2013: The Physical Science Basis: Contribution of Working Group I to the Fifth Assessment Report of the Intergovernmental Panel on Climate Change Ch.12 (Cambridge Univ. Press, Cambridge, 2013).

3. Smith, D. M. et al. The Polar Amplification Model Intercomparison Project (PAMIP) contribution to CMIP6: investigating the causes and consequences of polar amplification. Geosci. Model Dev. 12, 1139-1164 (2019).

4. Francis, J. A. \& Vavrus, S. J. Evidence linking Arctic amplification to extreme weather in midlatitudes. Geophys. Res. Lett. 39, L06801 (2012).

5. Cohen, J. et al. Recent Arctic amplification and extreme mid-latitude weather. Nature Geosci. 7, 627-637 (2014).

6. Barnes, E. A. \& Screen, J. A. The impact of Arctic warming on the midlatitude jet-stream: Can it? Has it? Will it? Wiley Interdiscip. Rev.: Clim. Change 6, 277-286 (2015).

7. Coumou, D., Capua, G. D., Vavrus, S., Wang, L. \& Wang, S. The influence of Arctic amplification on mid-latitude summer circulation. Nature Commun. 9, 2959 (2018).

8. Previdi, M., Smith, K. L. \& Polvani, L. M. Arctic amplification of climate change: a review of underlying mechanisms. Environ. Res. Lett. 16, 093003 (2021).

9. Henderson, G. R. et al. Local and Remote Atmospheric Circulation Drivers of Arctic Change: A Review. Front. Earth Sci. 9, 549 (2021).

10. Dai, A., Luo, D., Song, M. \& Liu, J. Arctic amplification is caused by sea-ice loss under increasing $\mathrm{CO}_{2}$. Nature Commun. 10, 1-13 (2019).

11. Blackport, R. \& Kushner, P. J. The role of extratropical ocean warming in the coupled climate response to Arctic Sea ice loss. J. Clim. 31, 9193-9206 (2018). 
12. Deser, C., Robert, A. T. \& Sun, L. The role of ocean-atmosphere coupling in the zonal-mean atmospheric response to Arctic sea ice loss. J. Clim. 28, 2168-2186 (2015).

13. Cai, M. Dynamical greenhouse-plus feedback and polar warming amplification. Part I: A dry radiative-transportive climate model. Clim. Dynam. 26, 661-675 (2006).

14. Cai, M. \& Lu, J. Dynamical greenhouse-plus feedback and polar warming amplification. Part II: Meridional and vertical asymmetries of the global warming. Clim. Dynam. 29, 375-391 (2007).

15. Hwang, Y. T., Frierson, D. M. W. \& Kay, J. E. Coupling between Arctic feedbacks and changes in poleward energy transport. Geophys. Res. Lett. 38, 17 (2011).

16. Yoo, C., Feldstein, S. \& Lee, S. The impact of the Madden-Julian Oscillation trend on the Arctic amplification of surface air temperature during the 1979-2008 boreal winter. Geophys. Res. Lett. 38, 24 (2011).

17. Spielhagen, R. F. et al. Enhanced modern heat transfer to the Arctic by warm Atlantic water. Science 331, 450-453 (2011).

18. Screen, J. \& Francis, J. A. Contribution of sea-ice loss to Arctic amplification is regulated by Pacific Ocean decadal variability. Nature Clim. Change 6, 856-860 (2016).

19. Chemke, R., Polvani, L. M., Kay, J. E. \& Orbe, C. Quantifying the role of ocean coupling in Arctic amplification and sea-ice loss over the 21st century. NPJ Clim. Atmos. Sci. 4, 1-9 (2021).

20. Alexeev, V. A., Langen, P. L. \& Bates, J. R. Polar amplification of surface warming on an aquaplanet in "ghost forcing" experiments without sea ice feedbacks. Clim. Dynam. 24, 655666 (2005).

21. Cronin, T. W. \& Tziperman, E. Low clouds suppress Arctic air formation and amplify highlatitude continental winter warming. Proc. Natl. Acad. Sci. USA 112, 11490-11495 (2015).

22. Taylor, P. C. et al. A decomposition of feedback contributions to polar warming amplification. J. Clim. 26, 7023-7043 (2013).

23. Graversen, R. G., Langen, P. L. \& Mauritsen, T. Polar amplification in CCSM4: Contributions from the lapse rate and surface albedo feedbacks. J. Clim. 27, 4433-4450 (2014). 
24. Pithan, Felix. \& Mauritsen, T. Arctic amplification dominated by temperature feedbacks in contemporary climate models. Nature Geosci. 7, 181-184 (2014).

25. Stuecker, M. F. et al. Polar amplification dominated by local forcing and feedbacks. Nature Clim. Change 8, 1076-1081 (2018).

26. Hahn, L. C., Armour, K. C., Zelinka, M. D., Bitz, C. M. \& Donohoe, A. Contributions to Polar Amplification in CMIP5 and CMIP6 Models. Front. Earth Sci. 9, 725 (2021).

27. Latonin, M. M., Bashmachnikov, I. L., Bobylev, L. P. \& Davy, R. Multi-model ensemble mean of global climate models fails to reproduce early twentieth century Arctic warming. Preprint at https://doi.org/10.1016/j.polar.2021.100677 (2021).

28. Davy, R., Chen, L. \& Edward, H. Arctic amplification metrics. Int. J. Climatol. 38, 4384-4394 (2018).

29. Bekryaev, R. V., Polyakov, I. V. \& Alexeev, V. A. Role of polar amplification in long-term surface air temperature variations and modern Arctic warming. J. Clim. 23, 3888-3906 (2010).

30. Chylek, P., Folland, C. K., Lesins, G., Dubey, M. K. \& Wang, M. Arctic air temperature change amplification and the Atlantic Multidecadal Oscillation. Geophys. Res. Lett. 36, L14801 (2009).

31. Barnes, E. A. \& Polvani, L. M. CMIP5 projections of Arctic amplification, of the North American/North Atlantic circulation, and of their relationship. J. Clim. 28, 5254-5271 (2015).

32. Yoshimori, M., Watanabe, M., Abe-Ouchi, A., Shiogama, H. \& Ogura, T. Relative contribution of feedback processes to Arctic amplification of temperature change in MIROC GCM. Clim. Dynam. 42, 1613-1630 (2014).

33. Winton, M. Amplified Arctic climate change: What does surface albedo feedback have to do with it? Geophys. Res. Lett. 33, L03701 (2006).

34. Holland, M. M. \& Bitz, C. M. Polar amplification of climate change in coupled models. Clim. Dynam. 21, 221-232 (2003).

35. Park, H. S., Kim, S. J., Stewart, A. L., Son, S. W. \& Seo, K. H. Mid-Holocene Northern Hemisphere warming driven by Arctic amplification. Sci. Adv. 5, eaax8203 (2019). 
36. Marcott, S. A., Shakun, J. D., Clark, P. U. \& Mix, A. C. A reconstruction of regional and global temperature for the past 11,300 years. Science 339, 1198-1201 (2013).

37. Sundqvist, H. S. et al. Arctic Holocene proxy climate database-new approaches to assessing geochronological accuracy and encoding climate variables. Clim. Past 10, 1605-1631 (2014).

38. Bartlein, P. J. et al. Pollen-based continental climate reconstructions at 6 and $21 \mathrm{ka}$ : a global synthesis. Clim. Dynam. 37, 775-802 (2011).

39. Masson-Delmotte, V. et al. Past and future polar amplification of climate change: climate model intercomparisons and ice-core constraints. Clim. Dynam. 26, 513-529 (2006).

40. Miller, G. H. et al. Arctic amplification: can the past constrain the future? Quat. Sci. Rev. 29, $1779-1790(2010)$.

41. Liu, Z. et al. Transient Simulation of Last Deglaciation with a New Mechanism for BøllingAllerød Warming. Science 325, 310-314 (2009).

42. Screen, J. A. et al. Consistency and discrepancy in the atmospheric response to Arctic sea-ice loss across climate models. Nature Geosci. 11, 155-163 (2018).

43. Navarro, J. C. A. et al. Amplification of Arctic warming by past air pollution reductions in Europe. Nature Geosci. 9, 277-281 (2016).

44. Beer, E., Eisenman, I. \& Wagner, T. J. W. Polar amplification due to enhanced heat flux across the halocline. Geophys. Res. Lett. 47, doi:10.1029/e2019GL086706 (2020).

45. Jenkins, M. \& Dai, A. The Impact of Sea-Ice Loss on Arctic Climate Feedbacks and Their Role for Arctic Amplification. Geophys. Res. Lett. 48, doi:10.1029/e2021GL094599 (2021).

46. Chylek, P. C., Folland, C. K., Lesins, G. \& Dubey, M. K. Twentieth century bipolar seesaw of the Arctic and Antarctic surface air temperatures. Geophys. Res. Lett. 37, L08703 (2010).

47. Hakim, G. J. et al. The last millennium climate reanalysis project: Framework and first results. J. Geophys. Res.: Atmos. 121, 6745-6764 (2016).

48. O'Neill, B. C. et al. The scenario model intercomparison project (ScenarioMIP) for CMIP6. Geosci. Model Dev. 9, 3461-3482 (2016). 


\section{Figures}
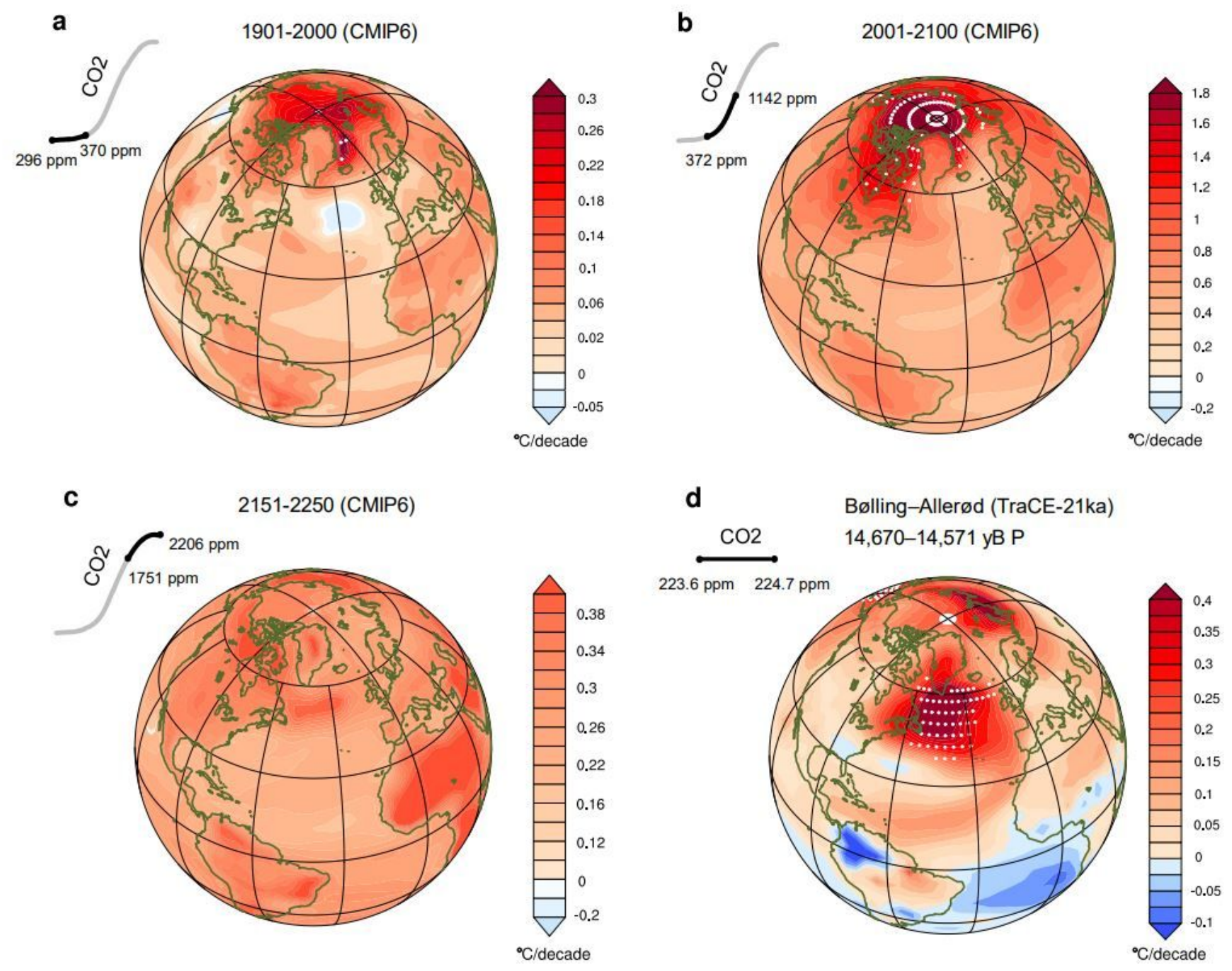

\section{Figure 1}

Spatial patterns of 2m air temperature trends. a, Ensemble mean in CMIP6 1901-2000 historical run. b, Ensemble mean in CMIP6 2001-2100 under SSP5-8.5 scenario. c, Ensemble mean in CMIP6 2251-2250 under SSP5-8.5 scenario. d, One 100-year sample in the Bølling-Allerød warming period. White dots mark the areas where sea ice decline significantly within the 100-year window (defined as the difference of sea ice concentration between the-last-20-year and the-first-20-year is greater than 10\%). Curves on the upperleft corner of each subplot are $\mathrm{CO} 2$ changes during the corresponding century. 


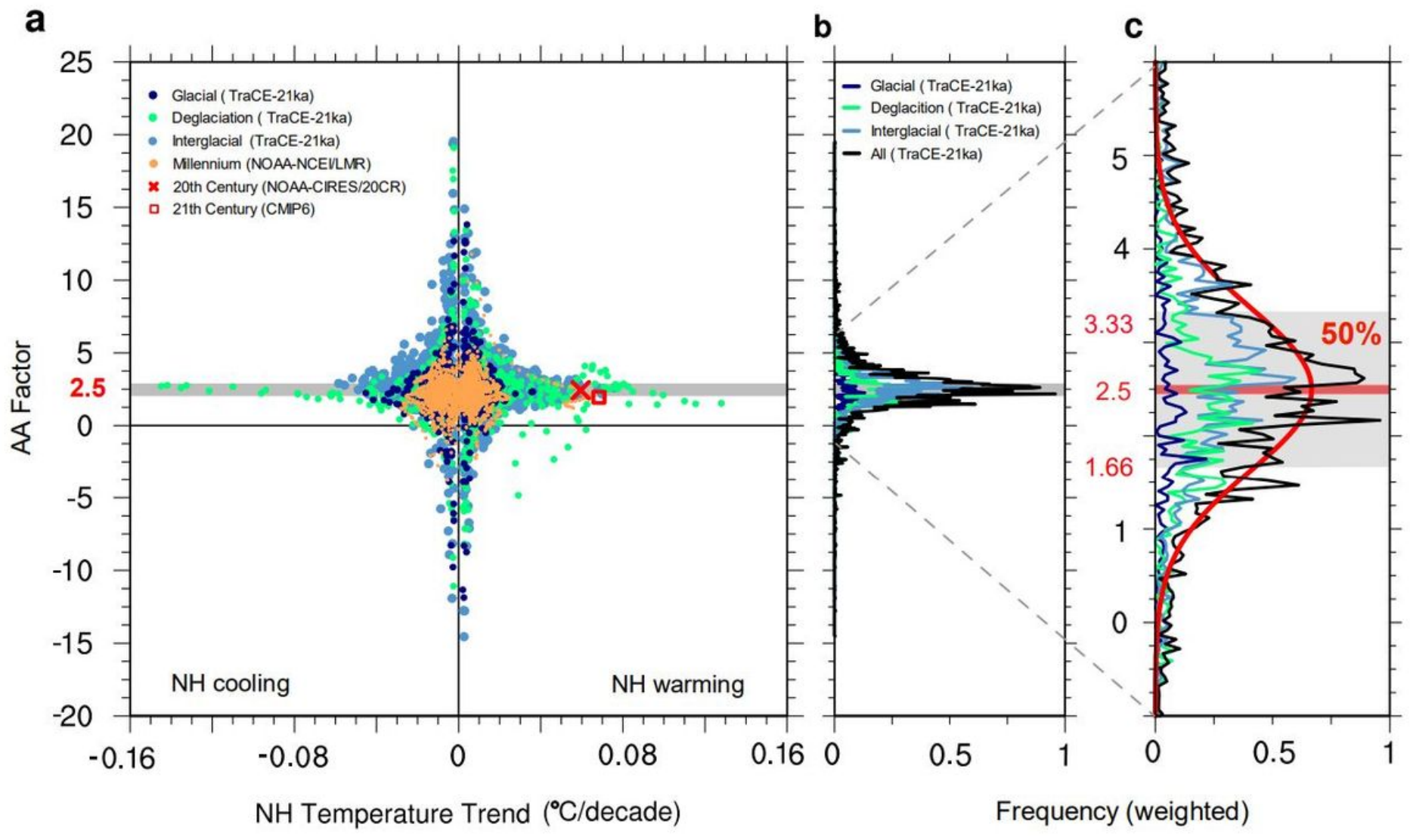

Figure 2

AA factor distribution. a, AA factor (see Method) and corresponding $\mathrm{NH} 2 \mathrm{~m}$ air temperature trends in glacial period (navy blue dots), deglaciation (green dots), interglacial period (steel blue dots), the last millennium 1-2000 C.E. (NOAA-NCEI/LMR, orange dots), the 20th century (NOAA-CIRES/20CR, red cross), and the 21th century (CMIP6 ensemble under SSP5-8.5, red square, should $x 10$, near $0.7 \otimes /$ decade). Thick grey line represents the AA's median 2.5. b, Weighted frequency distribution of AA factor (see Method). Black line represents the sum of glacial, deglaciation, and interglacial periods. c, Zoom-in of subplot b between -1 and 6 with a Gaussian fitting curve (red line). Red bar is the median of Gaussian fitting. Grey shadow refers to the AA's spread accounting for its $50 \%$ variance. 
a

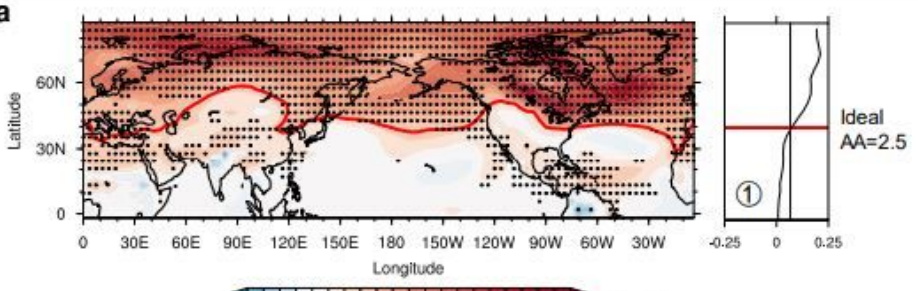

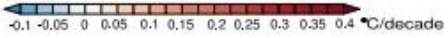

c
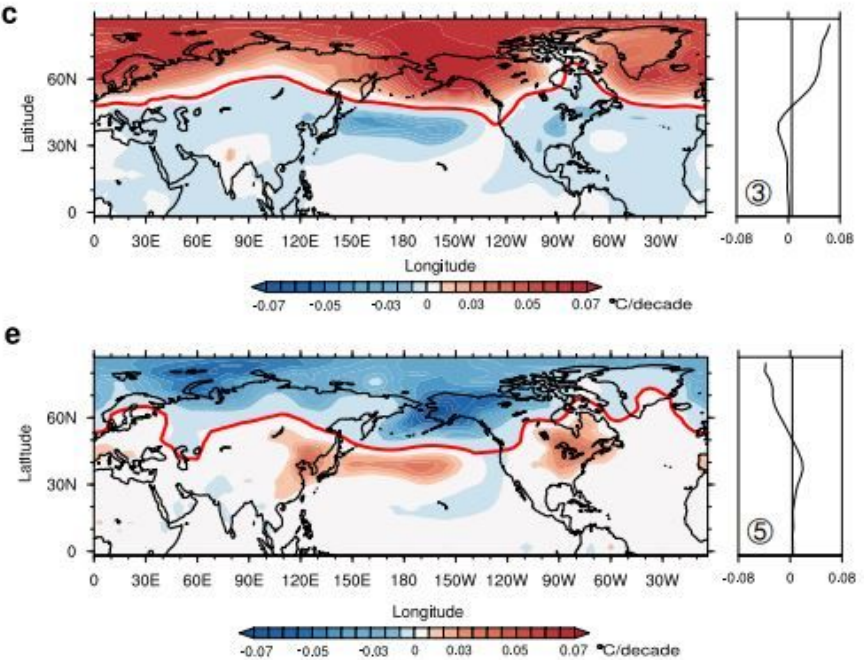

g

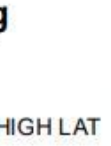

LOW LAT

$\mathrm{NH}$ b

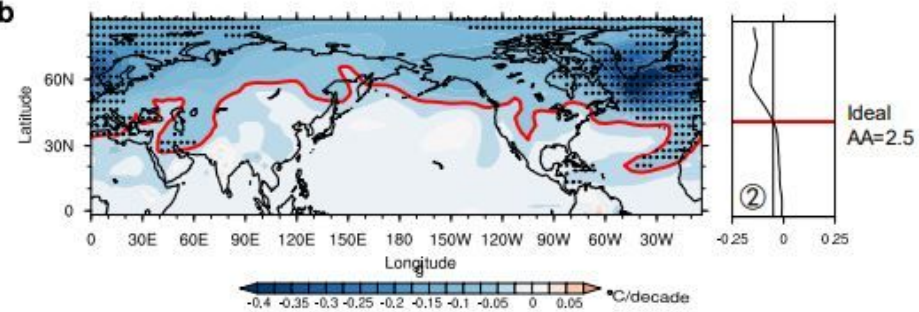

d

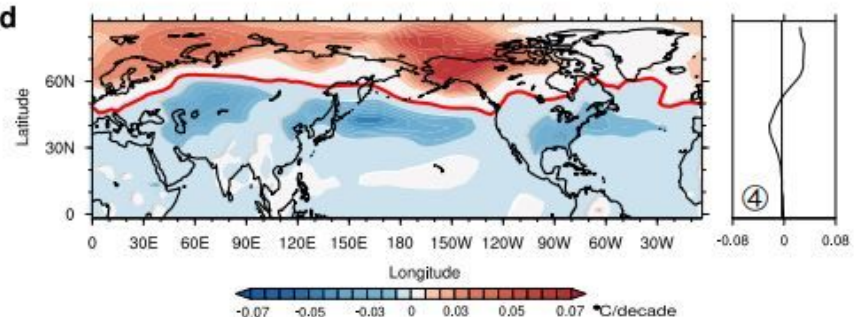

f

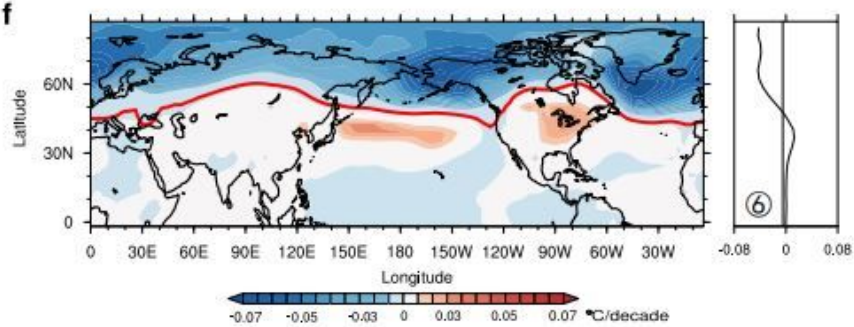

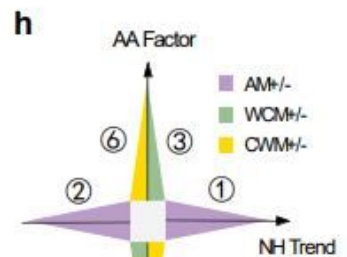

(4)

(5)

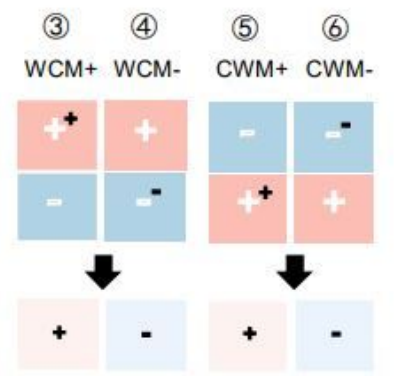

\section{Figure 3}

Composite spatial patterns of $2 \mathrm{~m}$ air temperature trends in 3 modes in TraCE-21 ka. a-b, Composite of cases with $\mathrm{NH}$ temperature trends larger than $0.2 \nabla / 100 a$ (a) or smaller than $-0.2 \varangle / 100 a$ (b). c-d, Composite of cases with $\mathrm{NH}$ temperature trends are 0-to-0.2 $\otimes / 100 \mathrm{a}$ and $\mathrm{AA}$ factor greater than 6 (c), or $\mathrm{NH}$ temperature trends are -0.2 -to- $0 \mathrm{Q} / 100 \mathrm{a}$ and $\mathrm{AA}$ factor smaller than -4 (d). e-f, Composite of cases with $\mathrm{NH}$ temperature trends are 0 -to- $0.2 \otimes / 100 \mathrm{a}$ and $\mathrm{AA}$ factor smaller than $-4(\mathrm{e})$, or $\mathrm{NH}$ temperature trends are -0.2 -to- 0 \&/100a and AA factor greater than 6 (f). Red contours are the $\mathrm{NH}$ average. Black dots mark areas with trend passing $95 \%$ significance test. Boxes right to the maps are zonal mean SAT trends. Vertical lines are the $\mathrm{NH}$ average. Red horizontal lines are the critical latitude in the simplified AA model with AA factor assuming to be 2.5 (see Method). g, Conceptual illustration of 3 modes. h, Corresponding regimes of 3 modes in the diamond-shape diagram as shown in Fig 2. 

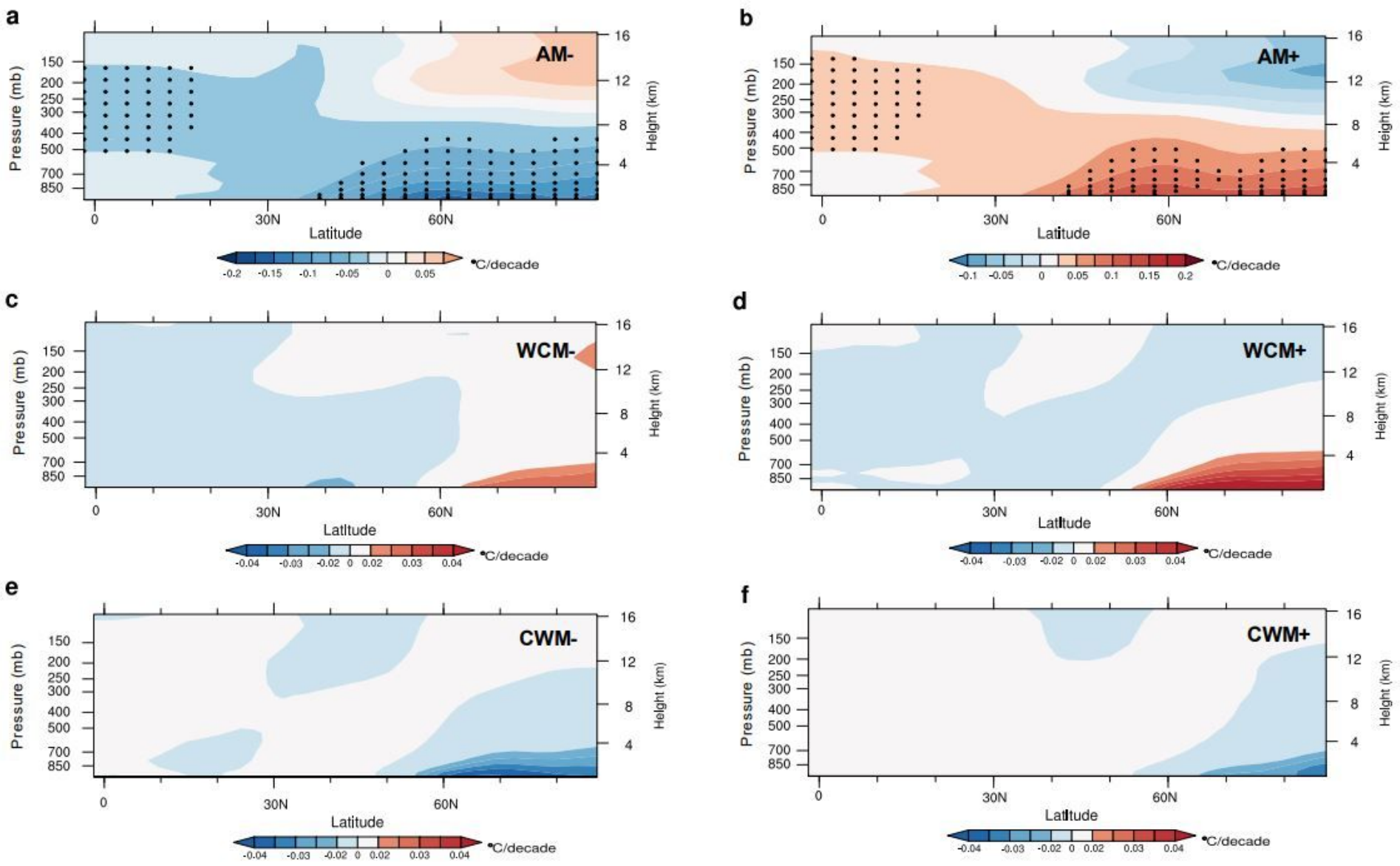

\section{Figure 4}

Composite cross-sections of zonally-averaged temperature trends in 3 modes in TraCE- $21 \mathrm{ka}$. The layout are the same as Fig 3 a-f, but for zonally-averaged temperature trends at multiple pressure levels. Black dots mark the areas with trend passing $95 \%$ significance test. 

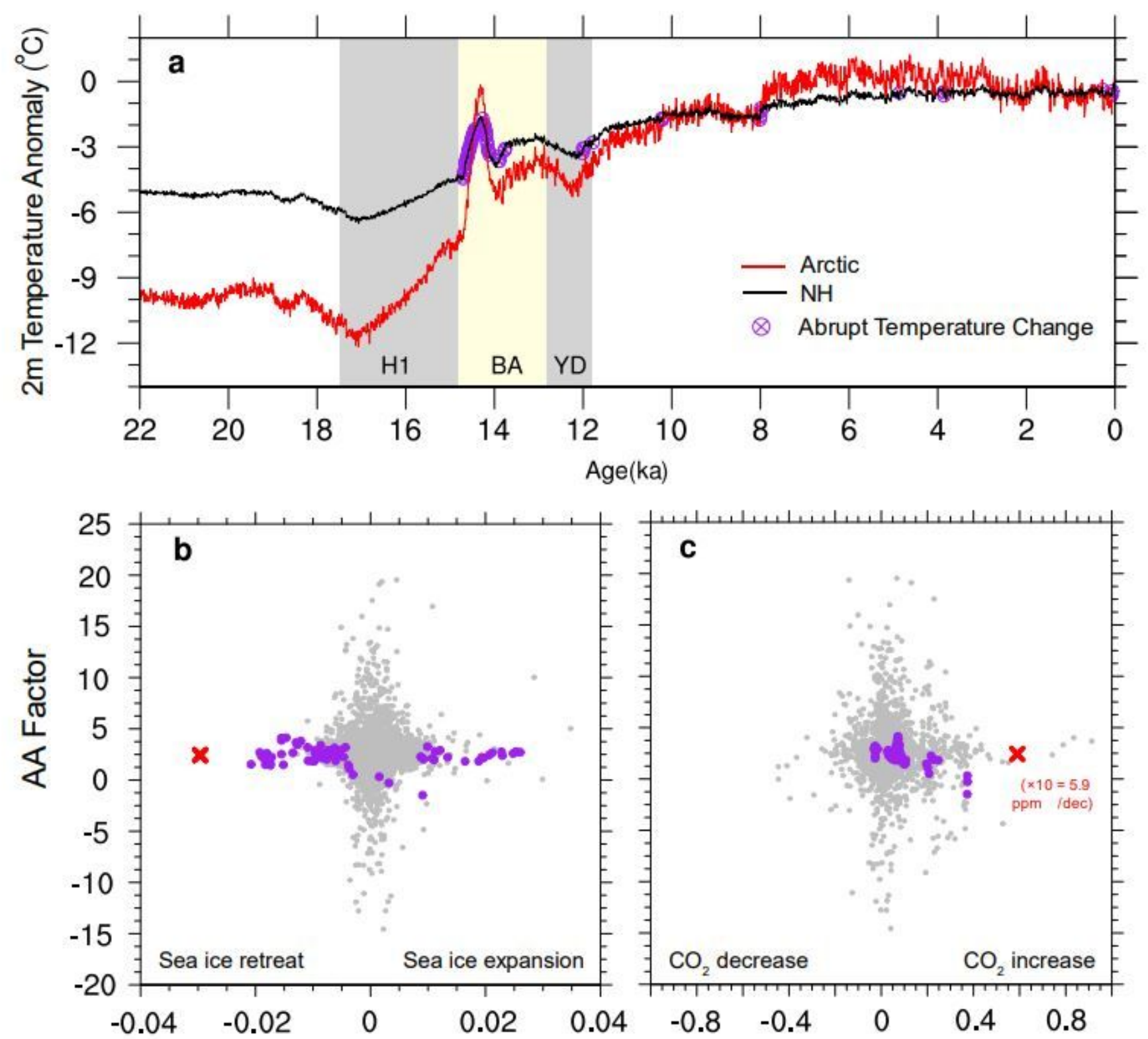

$\mathrm{NH}$ Sea Ice Area Trend $\left(\times 6371 \mathrm{~km}^{2} /\right.$ decade)

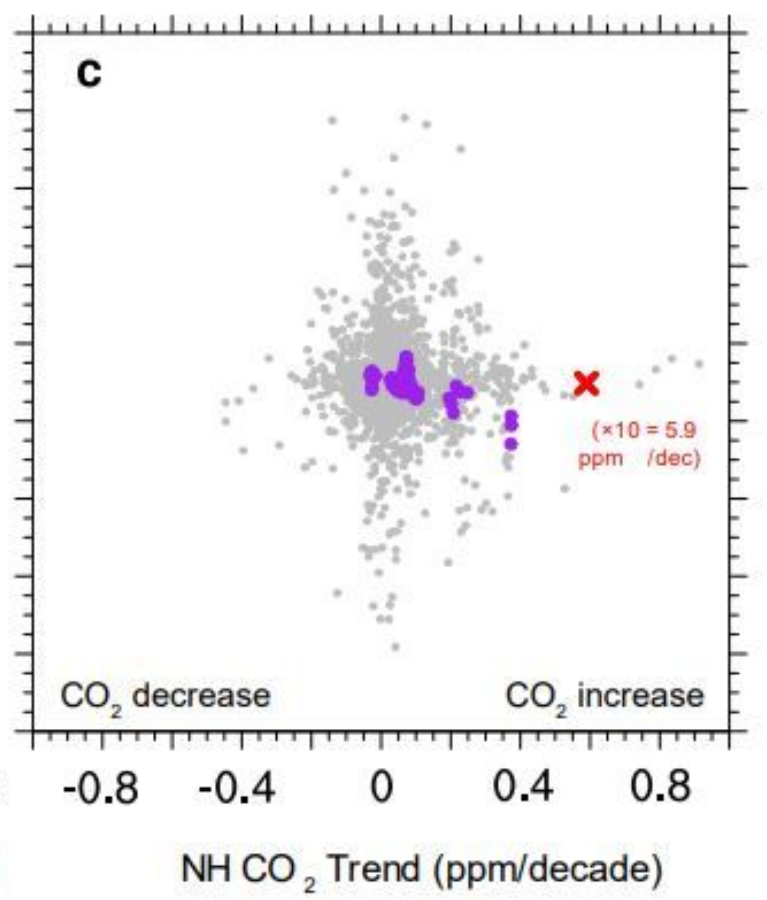

Figure 5

Sea ice and $\mathrm{CO} 2$ changes with respect to AA factor in abundant abrupt climate change (ACC) events. a, $\mathrm{NH}$ (black) and Arctic (red) $2 \mathrm{~m}$ air temperature evolution in the last 21,000 years in TraCE-21 ka. Purple circles highlight the samples having temperature trends larger than $\pm 0.5 \otimes / 100 a$. b, AA factor and corresponding $\mathrm{NH}$ sea ice area trends. c, AA factor and corresponding $\mathrm{NH} \mathrm{CO} 2$ concentration trends. Purple dots are same cases as purple circles in a. Red crosses are the 20th century ensemble mean of CMIP6.

\section{Supplementary Files}

This is a list of supplementary files associated with this preprint. Click to download. 
- AApapersupplement.pdf 